IRA-International Journal of Management \& Social Sciences

ISSN 2455-2267; Vol.08, Issue 01 (July 2017)

Pg. no. 1-7

Institute of Research Advances

http://research-advances.org/index.php/RAJMSS

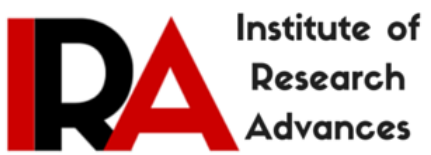

\title{
Antecedents of Work Life Balance: A Study of Healthcare Sector
}

Prof. Parvin Shaikh

Assistant Professor, Datta Meghe Institute of Management Studies, Nagpur, India.

Dr. Ujwala Dange

Head, Department of Management, J. D. College of Engineering \& Management, Nagpur, India.

Type of Review: Peer Reviewed.

DOI: http://dx.doi.org/10.21013/jmss.v8.n1.p1

\section{How to cite this paper:}

Shaikh, P., \& Dange, U. (2017). Antecedents of Work Life Balance: A Study of Healthcare Sector. IRAInternational Journal of Management \& Social Sciences (ISSN 2455-2267), 8(1), 1-7. doi:http://dx.doi.org/10.21013/jmss.v8.n1.p1

(C) Institute of Research Advances.

\section{(cc) BY-No}

This work is licensed under a Creative Commons Attribution-Non Commercial 4.0 International License subject to proper citation to the publication source of the work.

Disclaimer: The scholarly papers as reviewed and published by the Institute of Research Advances (IRA) are the views and opinions of their respective authors and are not the views or opinions of the IRA. The IRA disclaims of any harm or loss caused due to the published content to any party.

Institute of Research Advances is an institutional publisher member of Publishers Inter Linking Association Inc. (PILA-CrossRef), USA. The institute is an institutional signatory to the Budapest Open Access Initiative, Hungary advocating the open access of scientific and scholarly knowledge. The Institute is a registered content provider under Open Access Initiative Protocol for Metadata Harvesting (OAI-PMH).

The journal is indexed \& included in WorldCat Discovery Service (USA), CrossRef Metadata Search (USA), WorldCat (USA), OCLC (USA), Open J-Gate (India), EZB (Germany) Scilit (Switzerland), Airiti (China), Bielefeld Academic Search Engine (BASE) of Bielefeld University, Germany, PKP Index of Simon Fraser University, Canada. 


\begin{abstract}
The nature of their work requires the healthcare professionals to work in shifts, work overtime, report to duty at odd hours, take care of people who are sick and are sometimes terminally ill. Apart from draining them of physical energy, being in contact with such people also has a bearing on their psychological health. Striking a balance between life and work is a daunting task for the healthcare professionals. This study aimed at identifying the determinants of work life balance among Health care professionals, because they play a critical role in determining the efficiency, effectiveness and sustainability of health care systems. Data was collected from Healthcare Professionals like Physicians, Nurses, Clinical Support Staff and Administrative staff from both the Public and Private Hospitals in Nagpur District using a structured questionnaire. Factor Analysis revealed five factors namely Demographic Factors, Supportive Work Culture, Working Conditions, Work Provisions and Travelling distance from work that significantly affect the Work Life Balance of Healthcare Professionals. These findings will help the Healthcare Organizations to focus on Organizational interventions for helping their employees achieve a balance between the domains of work and life.
\end{abstract}

Key words: Work Life Balance, Healthcare Professionals, Organizational interventions.

\title{
I.Introduction:
}

Work-Life Balance (WLB) has been an issue of concern for the last few decades. The current context of globalization and the changing nature of work have provided the impetus for this topic. Gone are the days when the employees used to spend their entire lifetime in a single company. Periodic career changes for better opportunities, higher packages and supportive work culture is the norm of the day. Throughout the world there is an increase in self-employment, contract work and temporary work. In the context of Globalization, the contemporary work setting is characterized by fast pace of change, intense pressure and constant deadlines. Increased use of technology and the co-existing virtual workplace has blurred the boundaries between work and family life. With an increase in average income and rise in living standards individuals now are striving for better work atmosphere, improved family and personal life. Today is the time when employees want it all. It is not restricted to one domain of work or life but rather a rich synthesis of the two (Shankar \& Bhatnagar, 2010). Clark (2000) defines balance as "satisfaction and good functioning at work and at home with a minimum of role conflict". Thus, Work-Life Balance (WLB) is a term that refers to the desire on the part of both employees and employers to achieve a balance between workplace obligations and personal responsibilities. Bailyn et al. (2001) defined work /life balance as harmonious and holistic integration of work and non-work, so that men and women can achieve their potential across the domains in which they play out their life roles.

In many countries employers pay close attention to the subjective well-being of their employees and its impact on their jobs. Consequently, the subject of 'work-life balance' is now becoming the focal point of study by HRM experts and their managing teams. Work-life balance practices have direct influence on employee's retention and it also enhances organizational performance. Organizations need to improve their practices in order to improve organizational performance, including enhanced social exchange processes, increased cost savings, improved productivity and reduced turnover (Garg et al, 2016). Perceived availability and utilization of Work-Life initiatives are positively related to job satisfaction and reduced work pressure (Quazi, Koh, 2011; Forsyth et al, 2007). Work family enrichment acts as a mediator between organizational interventions for Work Life Balance and job outcomes (Baral \& Bhargava, 2010).

\section{II.Background for the Study}

The nature of their work requires the healthcare professionals to work in shifts, work overtime, report to duty at odd hours, take care of people who are sick and are sometimes terminally ill. Apart from draining them of physical energy, being in contact with such people also has a bearing on their psychological health. Striking a balance between life and work is a daunting task for the healthcare professionals. The recent trends in Healthcare like growing population, increasing affluence and awareness about healthcare will be putting a lot of burden on Healthcare system. Confounding the problem are the challenges like shortage of skilled and qualified professionals, scarcity of physical resources and urban rural disparity. It is important to study the determinants of 
work life balance among Health care professionals, because they play a critical role in determining the efficiency, effectiveness and sustainability of health care systems.

\section{III.Literature Review}

A large number of studies have been conducted on factors affecting Work life balance. Padmasiri. M. K.D. et al (2016) studied the impact of demographical factors on Work Life Balance among academic staff of University of Kelaniya. They established that there is a significant impact of gender and marital status on Work Life Balance as demographic factors. Lajtman (2016) made contribution to the work-family literature oriented in explaining work life conflict. Results of his study show that work has more impact on life as compared to the impact of life on work. The marital status emerged as a significant predictor of work life conflict because married young professionals reported significantly higher levels of work life conflict compared to others. Sadhvi (2015) identified the factors that may lead to work-life imbalance especially in women in IT Sector. She concluded that though all female employees seek family support, the family structure does not significantly affect work-life balance. Apart from Age group and Marital status, other factors which came into highlight are Company Policy consisting of Holidays, Cultural leaves, Pooling of leaves, and Paid Maternity; Attitude of people (at home and office) and includes Spouse Support, Family's attitude, Superior's attitude and Colleagues attitude without which it is difficult for a women to continue their work; work flexibility and Transportation. G.Delina, Dr. R. Prabhakara Raya (2013) in their study of married working women revealed that Spouse's profession also had a significant effect on the work life balance, where the respondents with spouse's profession as Business were found to be the ones suffering the most with work-life balance closely followed by the spouse's profession marketing. Viktoria Flechl, (2009) investigated how women in senior management positions in Austria, Denmark and the UK, combine a successful career and family life. Findings from the study indicated that support from their family, help from their partners, and Companies' flexibility is the most important things needed by women to reach a satisfactory work-life balance. Lonnie Golden, et al (2011) concluded that The consequences of hours of employment for a worker's work-life interface depends not only on the number of hours of work but also whether a worker perceives that they have some discretion over the setting and timing of their work hours and schedule. When a worker perceives to lack such discretion, this may have at least as much adverse effect on work-life balance as working long or extra hours. Khalil Muhamad et al (2015) in a study of 100 respondents in one of government enforcement agency in Malaysia revealed that, workload was the most dominant factor affecting work-life balance, followed by role conflict. Muley Harshada (2014) examined the work-life balance of employees of IT companies in Mumbai. The importance of the workplace culture that enabled employees to attain a balance between work and life was highlighted in the results. It revealed the importance of supervisors' role in achieving work life balance.

Kundnani Neera et al (2015) identified working conditions, facilities, performance, support, independence, and satisfaction as affecting work life balance among bank employees in Jaipur, Rajasthan. Lakshmi et al (2013) found that marital status, working hours, requirement of flexibility, additional working hours and over time, number of dependents, childcare and reason for overtime, support of the functional head and ability to discuss freely the work life balance issues with the functional head are the variables which affect the WLB of women employees in Educational Institutes. Narayanan (2012) demonstrated that the work life balance of Software professionals working in IT sector is strongly influenced by the factors like Work place rigidity, Family circumstances, Personal commitments, Job contents, Situational issues and time management.

\section{IV.Objective of the study}

The study aims to identify the factors affecting Work Life Balance of Healthcare Professionals.

\section{V.Research Methodology}

Data was collected from the Healthcare Professionals belonging to Public and Private sector Hospitals in Nagpur district. Stratified Random Sampling technique was adopted for collecting the data from the respondents. Hospitals were first divided into 2 groups, viz, Public and Private Hospitals. Data was collected from 600 Doctors, 500 Nurses, 100 Clinical Support Staff, and 100 Administrative Staff belonging to both Public and Private Hospitals in the District. A self developed questionnaire was employed. Variables identified from Literature Review as having an impact on Work Life Balance were included in the questionnaire. The scale had 19 variables and Participants were required to respond on a five point Likert scale, where 5=Very Important, 4=Important, 3= Neutral, 2=Unimportant and 1=Very Unimportant. 


\section{VI.Data Analysis \& Interpretation}

Out of the total respondents, that $69 \%$ of the respondents were Females and the remaining $31 \%$ were Males. $42 \%$ of the Respondents belonged to the age group 31-40 years, whereas 31\% of the respondents were in the age group above 40 years and $27 \%$ were in the age group 20-30 years. Also, $80 \%$ of the respondents were married. $46 \%$ of the respondents were Physicians; $38 \%$ were Nurses; $8 \%$ were Clinical Support Staff and remaining $8 \%$ were Administrative Staff. 44\% respondents were with less than 10 years experience, 31\% had an experience between $10-20$ years and $25 \%$ had an experience of more than 20 years.

Table 1: Reliability Statistics

\begin{tabular}{|l|c|c|}
\hline \multicolumn{1}{|c|}{ Scale } & Items & Cronbach's Alpha \\
\hline Factors affecting Work Life Balance & 19 & 0.879 \\
\hline
\end{tabular}

Factor analysis was carried out to identify the factors affecting Work Life Balance.

Table 2: KMO and Bartlett's Test

\begin{tabular}{|l|l|r|}
\hline \multicolumn{2}{|l|}{ Kaiser-Meyer-Olkin Measure of Sampling Adequacy } & .875 \\
\hline \multirow{3}{*}{ Bartlett's Test of Sphericity } & Approx. Chi-Square & 10742.091 \\
\cline { 2 - 3 } & df & 171 \\
\cline { 2 - 3 } & Sig. & .000 \\
\hline
\end{tabular}

From Table 2, it can be seen that value of KMO statistics is 0.875 , which is greater than 0.5 , indicating that Factor analysis can be used for the given set of data. Further, Bartlett's test of sphericity indicates that correlation coefficient matrix is significant as indicated by the $p$ value corresponding to the chi square statistic. The $p$ value is 0.000 , which is less than 0.05 , the assumed level of significance, indicating the rejection of the null hypothesis that the correlation matrix of variables is insignificant.

Table 3: Total Variance Explained

\begin{tabular}{|c|c|c|c|c|c|c|c|c|c|}
\hline \multirow[t]{2}{*}{ Component } & \multicolumn{3}{|c|}{ Initial Eigen values } & \multicolumn{3}{|c|}{$\begin{array}{l}\text { Extraction Sums of Squared } \\
\text { Loadings }\end{array}$} & \multicolumn{3}{|c|}{$\begin{array}{c}\text { Rotation Sums of Squared } \\
\text { Loadings }\end{array}$} \\
\hline & Total & $\begin{array}{c}\% \text { of } \\
\text { Variance }\end{array}$ & $\begin{array}{c}\text { Cumulative } \\
\%\end{array}$ & Total & $\begin{array}{c}\% \text { of } \\
\text { Variance }\end{array}$ & $\begin{array}{c}\text { Cumulative } \\
\%\end{array}$ & Total & $\begin{array}{c}\% \text { of } \\
\text { Variance }\end{array}$ & $\begin{array}{c}\text { Cumulative } \\
\%\end{array}$ \\
\hline 1 & 6.556 & 34.507 & 34.507 & 6.556 & 34.507 & 34.507 & 3.906 & 20.560 & 20.560 \\
\hline 2 & 1.944 & 10.230 & 44.737 & 1.944 & 10.230 & 44.737 & 3.117 & 16.406 & 36.966 \\
\hline 3 & 1.448 & 7.621 & 52.358 & 1.448 & 7.621 & 52.358 & 2.264 & 11.915 & 48.881 \\
\hline 4 & 1.289 & 6.782 & 59.140 & 1.289 & 6.782 & 59.140 & 1.562 & 8.218 & 57.100 \\
\hline 5 & 1.119 & 5.890 & 65.030 & 1.119 & 5.890 & 65.030 & 1.507 & 7.930 & 65.030 \\
\hline 6 & .791 & 4.164 & 69.194 & & & & & & \\
\hline 7 & .754 & 3.968 & 73.161 & & & & & & \\
\hline 8 & .672 & 3.539 & 76.701 & & & & & & \\
\hline 9 & .653 & 3.438 & 80.139 & & & & & & \\
\hline 10 & .574 & 3.021 & 83.160 & & & & & & \\
\hline 11 & .526 & 2.769 & 85.930 & & & & & & \\
\hline 12 & .471 & 2.479 & 88.409 & & & & & & \\
\hline 13 & .447 & 2.353 & 90.762 & & & & & & \\
\hline 14 & .375 & 1.976 & 92.738 & & & & & & \\
\hline 15 & .351 & 1.846 & 94.585 & & & & & & \\
\hline 16 & .301 & 1.582 & 96.166 & & & & & & \\
\hline 17 & .275 & 1.450 & 97.616 & & & & & & \\
\hline 18 & .253 & 1.330 & 98.946 & & & & & & \\
\hline 19 & .200 & 1.054 & 100.000 & & & & & & \\
\hline
\end{tabular}


Table 3 indicates that there are five factors resulting from the analysis, explaining a total of $65.03 \%$ of the variations in the entire data set. The percentage of variation explained by the first, second, third, fourth and fifth factors are $20.560,16.406,11.915,8.218$ and 7.930 respectively after varimax rotation is performed.

Table 4: Rotated Component Matrix ${ }^{\mathrm{a}}$

\begin{tabular}{|l|r|r|r|r|r|}
\hline & \multicolumn{5}{|c|}{ Component } \\
\cline { 2 - 6 } & 1 & 2 & 3 & 4 & \multicolumn{1}{|c|}{5} \\
\hline F1 & .557 & .317 & .337 & .066 & -.298 \\
\hline F2 & .782 & .171 & .063 & .127 & -.104 \\
\hline F3 & .806 & .242 & .125 & .140 & .063 \\
\hline F4 & .815 & .073 & .137 & .114 & .071 \\
\hline F5 & .703 & .039 & .141 & .117 & .374 \\
\hline F6 & .063 & .386 & .458 & .497 & -.064 \\
\hline F7 & .238 & .794 & .269 & -.045 & .091 \\
\hline F8 & .053 & .824 & .097 & .166 & .073 \\
\hline F9 & .351 & .750 & .150 & .054 & .235 \\
\hline F10 & .590 & .507 & -.098 & .005 & .183 \\
\hline F11 & .434 & .150 & -.072 & .165 & .555 \\
\hline F12 & .042 & .094 & .164 & -.010 & .783 \\
\hline F13 & .117 & .254 & .618 & -.206 & .133 \\
\hline F14 & .048 & .037 & .778 & .175 & .180 \\
\hline F15 & .253 & .146 & .762 & .075 & -.091 \\
\hline F16 & .122 & .489 & .292 & .507 & -.016 \\
\hline F17 & .182 & .023 & -.078 & .836 & .125 \\
\hline F18 & .502 & .142 & .245 & -.064 & .289 \\
\hline F19 & .268 & .516 & .135 & .386 & -.269 \\
\hline Extraction Method: Principal Component Analysis. & \\
\hline Rotation Method: Varimax with Kaiser Normalization. & \\
\hline a. Rotation converged in 8 iterations. \\
\hline
\end{tabular}

Rotated Component matrix was used, using 0.5 as a cut off point for factor loading for naming the factors. The variables under each factor were identified and grouped together along with their factor loadings in Table 5.

Table 5: Variables under each Factor

\begin{tabular}{|c|l|l|}
\hline Factor & Variables/ Items & $\begin{array}{l}\text { Factor } \\
\text { Loadings }\end{array}$ \\
\hline I & Age & 0.557 \\
\hline & Gender & 0.782 \\
\hline & Marital Status & 0.806 \\
\hline & Family Size & 0.815 \\
\hline & Dependents (Aging parents/ children at home) & 0.703 \\
\hline & Support of Spouse & 0.590 \\
\hline & Spouse's working arrangements & 0.502 \\
\hline II & Support from Superior & 0.794 \\
\hline & Support from Peers & 0.824 \\
\hline & Support from Subordinate & 0.750 \\
\hline & Years of experience & 0.516 \\
\hline III & Working in shifts & 0.618 \\
\hline & Overtime & 0.778 \\
\hline & Work pressure & 0.762 \\
\hline IV & Orientation towards work and family & 0.507 \\
\hline & Working provisions & 0.836 \\
\hline V & Support of elder ones (Parents/ In laws) & 0.555 \\
\hline & Travelling distance from work & 0.783 \\
\hline
\end{tabular}


The First factor comprises of Variables like Age, Gender, Marital Status, Family Size, Dependents at home, Support of Spouse and Spouse's working arrangements. This can be named as DEMOGRAPHIC FACTORS. The Second Factor consists of variables Support from Superior, Support from Peers, Support from Subordinates and Years of Experience. This Factor can be named as SUPPORTIVE WORK CULTURE. The Third Factor has variables working in shifts, Overtime and Work pressure. This can be labelled as WORKING CONDITIONS. Fourth Factor with the variables, Orientation towards Work \& Family and Working Provisions can be called WORKING PROVISIONS. Last Factor with variables Support of elder ones in the family and Travelling/ Distance from work can be labelled as DISTANCE FROM WORK.

\section{VII.Results \& Discussion}

Thus the five factors that affect Work Life Balance are Demographic Factors, Supportive Work Culture, Working Conditions and Distance from Work. These findings are consistent with the findings from the Literature. Chandrasekhar (2013) reported strong association between demographic factors like gender \& marital status on work life balance. Walia Parminder (2015), also reported significant impact of Gender on Work life balance of employees. Georges et al (2010) had concluded that the organization of working hours has a determinant and major effect on individuals' work life balance satisfaction, with strong amplitude for women: the fact to have atypical hours (regularly working on evenings, nights or weekend), long hours (over 40 hours per week), irregular hours or hours determined by the employer distinctly increase dissatisfaction. Workload is also a dominant factor in affecting Work Life Balance (Khalil Muhamad, 2015).

\section{VIII.Conclusion}

The perception of Work Life Balance is strongly affected by how much importance is attached by the individual to the two domains. For some the preference may be to spend long hours at work, perhaps because of career stage, perhaps because of a limited life outside work. For others, the opposite may apply and balance is perceived to exist where some work takes place but it is subordinated to the demands of home. Though the demographic factors are beyond the control of organizations, they can very well control the Working conditions by talking measures to reduce overtime and pressure of work. Sincere efforts are needed in this direction. Hospitals can look forward to facilitate the internalization of a supportive Work culture. This needs to be taken care of particularly by the Public sector Hospitals, as Healthcare Professionals in this sector have enormous Patient load and also face threat to their security when dealing with the relatives of critically ill patients. Working provisions in the form of family friendly initiatives leaves provided by the Organizations etc influence the ability to manage the responsibilities of the two domains. Working Provisions like leave arrangements have not only to be made available, but their utilization by the employees has to be ensured. They should not be denied the much needed break citing shortage of staff.

\section{Scope for Future Research}

Further Research can be carried out for examining the Work Life Balance of Healthcare Professional and carrying out a comparative study between the two sectors, i.e, Public and Private Sector. Outcomes of Work

Life Balance in terms of organizational or individual outcomes can also be studied.

\section{References}

1. Bailyn, Lotte; Drago, Robert; and Kochan, Thomas A.; "Integrating Work and Family Life - A Holistic Approach". A Report of the Sloan Work-Family Policy Network. 9/14/2001: pp 1- 10.

2. Baral Rupashree, Bhargava Shivganesh, Work-family enrichment as a mediator between organizational interventions for work-life balance and job outcomes, Journal of Managerial Psychology (2010), Volume: 25, Issue: 3, Publisher: Emerald Group Publishing Limited, Pages: 274-300

3. Clark SC (2000) Work/family border theory: A new theory of work/family balance. Human Relations. 53(6): 747-770.

4. Delina G., R. Prabhakara Raya, A study on Work-Life Balance in Working Women, IRACST International Journal of Commerce, Business and Management (IJCBM), ISSN: 2319-2828, Vol. 2, No.5, October 2013, pg. 274-282

5. Forsyth Stewart, Debruyne Andrea Polzer, The organisational pay-offs for perceived work-life balance support, Asia Pacific Journal of Human Resources 2007; 45; 113, DOI: 10.1177/1038411107073610

6. Garg Preeti, Yajurvedi Neha, Impact of Work-Life Balance Practices on Employees Retention and Organizational Performance - A Study on IT Industry, Indian Journal of Applied Research, Volume: 6 | Issue: 8 | August 2016, pg. 105-108 
7. Khalil Muhamad Omar, Idaya Husna Mohd, Muhammad Shafiq Ariffin, Workload, Role Conflict and Work-Life Balance among Employees Of An Enforcement Agency in Malaysia, International Journal of Business, Economics and Law, Vol. 8, Issue 2 (Dec.), 2015, pg. 52-57

8. Kundnani Neera, Mehta Pallavi, Identifying the Factors Affecting Work-Life Balance of Employees in Banking Sector, PARIPEX - Indian Journal Of Research, Volume: 4 | Issue: 6| June 2015, pg. 328-331

9. Lajtman Mirna Korican, Impact of personal factors on the work life conflict and its co-infl uence with organizational factors on employee commitment in Croatia, Dissertation no. 4529 Mate d.o.o., Zagreb, 2016

10. Lakshmi Santhana K., T. Ramachandran, and David Boohene, Analysis of Work Life Balance of Female Nurses in Hospitals - Comparative Study between Government and Private Hospital in Chennai, TN., India, International Journal of Trade, Economics and Finance, Vol. 3, No. 3, June 2012

11. Lonnie Golden, The Effects of Working Time on Productivity and Firm Performance: a research synthesis paper, ILO, Geneva, 2011

12. Muley Harshada, An Empirical Analysis Of Factors Affecting Work Life Balance Among Information Technology Employees In Mumbai, Abhinav National Monthly Refereed Journal of Research in Commerce \& Management, Volume 3, Issue 11 (November, 2014), pg. 1-7

13. Narayanan A G V., R. Lakshmi Narayanan, An Empirical Study on Factors Affecting Work-Life Balance of IT Professionals, European Journal of Social Sciences, ISSN 1450-2267 Vol.31 No.3 (2012), pp. 302 313

14. Padamasiri Dinithi, Impact of Demographical Factors on Work Life Balance among Academic Staff of University of Kelaniya, Sri Lanka, Journal of Education and Vocational Research, Vol. 7, No. 1, pp. 54 59, March 2016

15. Quazi, H.A, Koh, M.H, Huang, Q., and Khoo, J.W. (2011), "Impact of Work-life Initiatives on Employee Behavior in Supply Chain Management Organizations in Singapore", POMS 22nd Annual Conference, USA.

16. Sadhvi, Study Of Factors In Work-Life Balance Among Women Employees In It Sector With Respect To Age, Marital Status And Family Structure, International Journal of Organizational Behaviour \& Management Perspectives, Volume 4, Number 2, April-June" 2015, pg. 1761-1768

17. Shankar Tara, Bhatnagar Jyotsna, A Model of Work Life Balance, Employee Engagement, Emotional Consonance/Dissonance \& Turnover Intention, Indian Journal of Industrial Relations, July, 2010, Volume: 46 Source Issue: 1

18. Viktoria Flechl, 2009, Work Life Balance - A comparative Study of Women in Senior Management Positions in Austria, Denmark and Great Britain, Munich, GRIN Publishing GmbH 